\title{
A NOVEL NORMULINANE ISOLATED FROM Azorella compacta AND ASSESSMENT OF ITS ANTIBACTERIAL ACTIVITY
}

\author{
A. SAN-MARTÍN $a^{*}$, M. BACHO , S. NÚÑEZ $Z^{b}, J . R O V I R O S A^{a}$, A. SOLER , \\ V. BLANC', R. LEÓN $N^{c} A N D$ A. F. OLEA \\ ${ }^{a}$ Faculty of Sciences, Universidad de Magallanes, Punta Arenas, Chile \\ ${ }^{b}$ Department of Chemistry, School of Sciences, Universidad de Chile, Santiago, Chile \\ 'Department of Microbiology, Dentaid Research Center, Barcelona, España \\ ${ }^{d}$ Instituto de Ciencias Quimicas Aplicadas, Universidad Autónoma de Chile, Santiago, Chile
}

\begin{abstract}
Phytochemical analysis of Azorella compacta resulted in the isolation of six known diterpenes and one unknown norditerpene using chromatographic methods. The structure of this new compound was established by spectroscopic analysis. The bioactivity of the new compound was assessed against six oral bacteria using a drop test method. A high level of growth inhibition was observed against $F$. nucleatum and $P$. gingivalis; however, other species such as $V$. parvula and A. actinomycetemcomitans were not affected.
\end{abstract}

Keywords: Azorella compacta; diterpenes; normulinane, yareta.

\section{Introduction}

Phytochemical data on the Apiaceae family indicate that the most common compounds found in these plants are coumarins and sesquiterpenes, although some alkaloids (hemlock) have also been detected as minor components. Meanwhile, studies on tribe Mulinae species (Azorella, Laretia and Mulinum genera) have reported the presence of terpenes as main components ${ }^{1}$, while a few known flavonoids and aromatic compounds have also been isolated ${ }^{2,3}$

In spite of this fact, a new chalcone was recently reported ${ }^{4}$, and three known sesquiterpenes have been also isolated, among them spathulenol an outstanding compound presenting a cyclopropane ring in its structure (San-Martín, A. unpublished data). This structural feature is also present in some diterpenes with azorellane ${ }^{3,5}$ skeleton, and in a triterpene known as cycloartenol ${ }^{6}$. Earlier research on tribe Mulinae has led to depiction of about 30 new diterpenoids that present structural features with no evidence of synthetic or natural sources ${ }^{1}$. These compounds, only detected in tribe Mulinae, present mulinane, azorellane, yaretane and madreporane skeletons. The most frequent chemical functions present in mulinane diterpenes are unsaturations and hydroxylations of the 7-membered ring. Frequently, compounds with carboxylic acid appea in position 20. So far, information on the organic functions of 5-membered ring compounds or on the isopropyl group is scarce? Recently, the absolute configuration of a diterpene from Azorella was determined by vibrationa circular dichroism spectroscopy ${ }^{8}$, and also the synthesis of four mulinane diterpenoids has been reported ${ }^{9}$. The plants studied were gathered mostly in Chile, although a few other studies have used specimens collected in Argentina ${ }^{10,11}$ and Perú ${ }^{12}$. Continuing the search for bioactive compounds in plants of the Azorella genus, in this paper we describe the isolation of normulin11-en-13-oxo-20-oic acid, a norditerpene that has not been isolated before (1, see Figure 1), together with six known diterpenes from A. compacta, as well as our findings on the effects of $\mathbf{1}$ against oral bacteria. a)

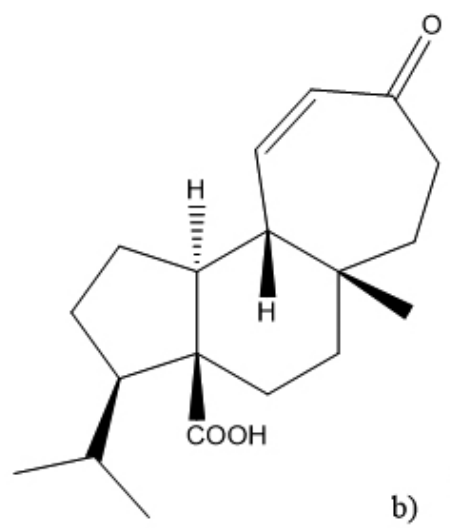

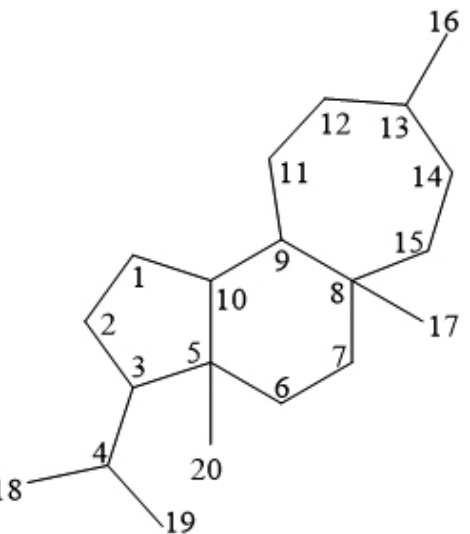

Figure 1: a) Structure of normulin-11-en-13-oxo-20-oic acid (1); b) Mulinane skeleton

\section{EXPERIMENTAL}

Column chromatography was performed using $0.040-0.063 \mathrm{~mm}$ Merck silica gel and the exclusion chromatography was carried out using Sephadex LH-20. Purification was run on Isolera One using Biotage ${ }^{\circledR}$ Ultra $10 \mathrm{~g} \mathrm{HP}-$ sphere $25 \mu \mathrm{m}$ column. ${ }^{1} \mathrm{H}-\mathrm{NMR}$ spectra were registered by dissolving the samples in $\mathrm{CDCl}_{3}$ at $400.13 \mathrm{MHz}$, and ${ }^{13} \mathrm{C}$ - NMR spectra were registered at 125.03 MHz in a multidimensional Bruker Avance III HD-400 spectrometer Chemical displacements are expressed as values relative to TMS as an internal standard. Multiplicities are designated as singlets (s), doublets (d), triplets (t), quadruplets (q) and multiplets (m) and the NMR spectra were obtained using standard Bruker software. UV spectra were taken on a Shimadzu UV-160 spectrophotometer using $\mathrm{MeCN}$ as a solvent. IR spectra were registered using $\mathrm{KBr}$ tablets in the $500-4000 \mathrm{~cm}^{-1}$ region on a FT-IR Thermo Nicolet Nexus 670 spectrophotomenter with $0.125 \mathrm{~cm}^{-1}$ spectral resolution. Mass spectra were taken on a Micromass Q-TOF spectrometer.

\subsection{Plant Material}

The plant was gathered in Tatio (Antofagasta Region, Chile) in May of 2013. A live specimen of the species was left at the Herbarium of the Natural Products Laboratory of Faculty of Sciences, University of Chile, under the 
code No. 0513.

2.2 Extraction and isolation

The aerial part of $A$. compacta $(2.1 \mathrm{~kg})$ was grounded into a fine powder, which was extracted three times with $n$-hexane for 12 hours at room. After filtering, the dissolvent was evaporated at low temperature producing a rubber $(100.0 \mathrm{~g})$. The $n$-hexane fraction was adsorbed on silica gel and fractionated in a column containing silica gel $(20 \times 30 \mathrm{~cm}, 1000.0 \mathrm{~g})$, which was eluted using an $n$-hexane-EtOAc gradient with increasing amounts of EtOAc. After fractionation, the less polar fraction was submitted to exclusion chromatography using Sephadex LH-20 (10 x $130 \mathrm{~cm}$ of Size $)$ and a mixture of $n$-hexane: $\mathrm{CH} \mathrm{Cl}_{2}: \mathrm{MeOH}(3: 2: 1)$ as eluent. Finally, the relevant fraction was purified using Isolera ${ }^{\mathrm{TM}}$ equipment (Biotage ${ }^{\circledR}$ Ultra $10 \mathrm{~g}$ HP-sphere column, $30 \times 72 \mathrm{~mm}, 25 \mu \mathrm{m}, 7000 \mathrm{~N} / \mathrm{m}$ ) obtaining $20 \mathrm{mg}$ of new compound 1 . Likewise, the following were isolated from the remaining fractions: mulin-11, 13-dien-20-oic acid 2 (150 mg), azorellanol (30 mg) 3, epiazorellanol (5 mg) 4, mulinolic acid $5(25 \mathrm{mg})$, epimulinolic acid $6(20 \mathrm{mg})$ and mulin-12-en11,14-dioxo-20-oic acid 7 (40 mg). For isolated structures see figure 2. Known compounds were identified by comparison with authentic samples and with data from the literature ${ }^{13-17}$.
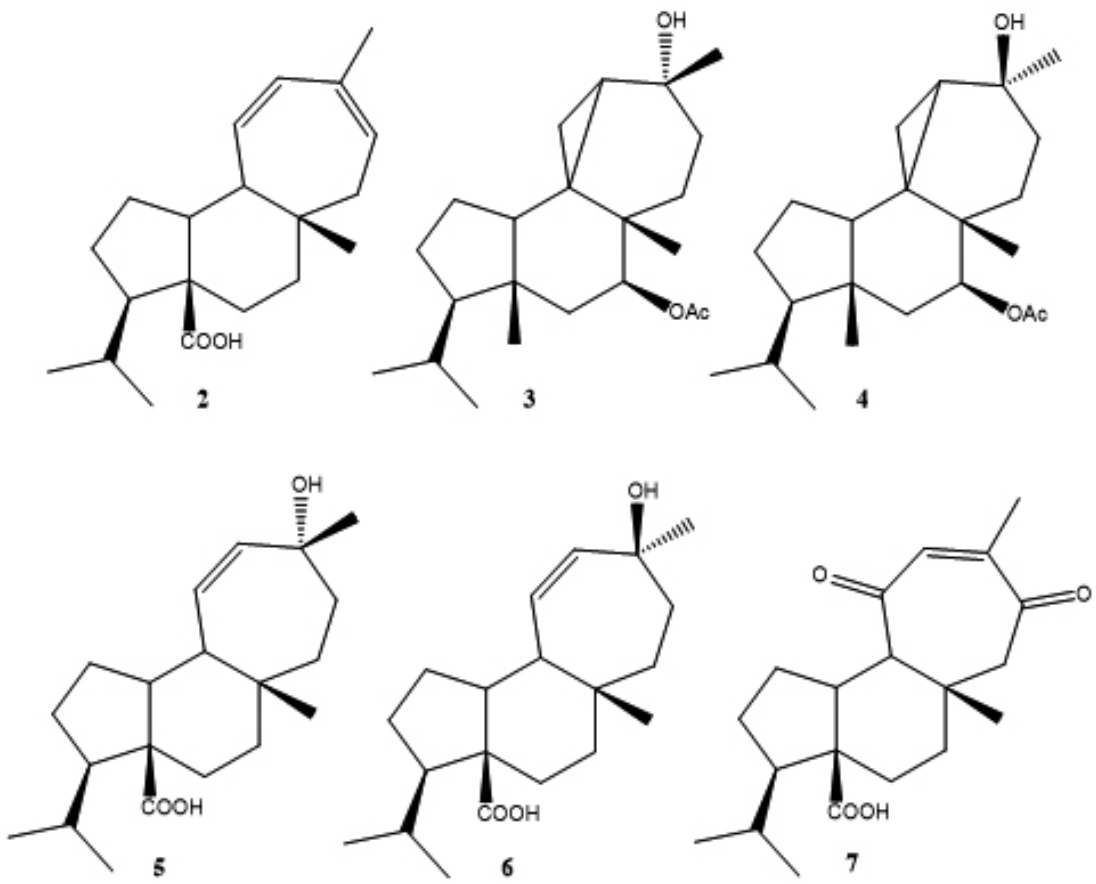

Figure 2: Other compounds isolated of Azorella compacta.

Compound 1: normulin-11-en-13-oxo-20-oic acid

Colorless solid. MP: $106^{\circ} \mathrm{C}$. IR (KBr) $v_{\max }: 3424(\mathrm{OH}), 2956,1692,1639$ $\mathrm{cm}^{-1}$. UV/Vis $\lambda_{\max }(\mathrm{MeCN}) \mathrm{nm}(\log \varepsilon): 232.5$. EIMS m/z (rel. Int. \%): 304.0 $\left[\mathrm{M}^{+}\right]$(21.94), 291.0 (14.18), 276.0 (98.90), 258.0 (34.40), 242.90 (26.58), 229.0 (14.81), 221.0 (41.42), 215.0 (100.0), 203.0 (25.94), 189.0 (32.63), 175.0 (48.65), 161.0 (19.80), 147.0 (30.19), 123.0 (50.12), 105.0 (49.58), 95.0 (48.51), 91.0 (54.68), 79.0 (52.51), 67.0 (36.49), 55.0 (72.05). HRMS-FAB: $m / z\left[\mathrm{M}+\mathrm{H}^{+}\right]$Calculated for $\mathrm{C}_{19} \mathrm{H}_{28} \mathrm{O}_{3}: 304.2038$, Found: 304.0193. For NMR data, see Table 1 and Figures S1-S4 (supplementary material).

\subsection{Preparation and characterization of polymer micelles}

Polymer micelles were prepared by direct dissolution of Pluronic F-127 in water at a concentration well above the critical micelle concentration CMC (1 $\mathrm{mM})^{18}$. The CMC was determined by a photophysical technique that consists in measuring the ratio $\mathrm{I}_{\mathrm{M}} / \mathrm{I}_{\mathrm{E}}$ of pyrene fluorescence as a function of polymer concentration. Steady-state fluorescence spectra of pyrene were recorded utilizing a Fluoromax 4 fluorometer (Horiba Jobin Yvon, Irvine, CA, USA). The size distributions of polymeric micelles were determined by dynamic light scattering (DLS) using a Zetasizer Nano ZS (Malvern Instruments, Malvern, UK)

This copolymer is biocompatible and it is listed in U.S. and British Pharmacopoeia as a pharmaceutical excipient. It has been proposed that the biological activity of poor-water soluble molecules can be improved by solubilization into these nanoaggregates ${ }^{19}$.

\subsection{Preparation of stock solutions}

Homogeneous stock solutions of compound 1-6 and extracts were formulated by dissolving $20-40 \mathrm{mg}$ in $500 \mu \mathrm{L}$ of DMSO. On the other hand, microheterogeneous solutions were obtained by using the emulsion method. Briefly, aliquots (100-500 $\mu \mathrm{L})$ of each extract and compound 1 dissolved in dichloromethane were added to $10 \mathrm{~mL}$ of an aqueous polymer solution (Pluronic F-127, $1 \mathrm{mM}$ ). After an emulsion has been formed, the organic solvent was eliminated by heating and sonication. In this process, non-polar compounds were incorporated into the hydrophobic micelle core reaching a concentration of $2000 \mathrm{ppm}$. Before their application to Petri plates these solutions were diluted to $650-1250 \mathrm{ppm}$, but keeping constant the polymer concentration $(1 \mathrm{mM})^{19}$.

\subsection{Antibacterial bioassay}

Six oral bacteria were used for antimicrobial activity testing. Streptococcus oralis DSM 20627, Veillonella parvula NCTC 11810, Fusobacterium nucleatum DSM 20482, Agreggatibacter actinomycetemcomitans DSM 8324, Actinomyces naeslundii DSM 17233 and Porphyromonas gingivalis ATCC 33277. Liquid cultures were prepared from single colonies transferred to modified brain heart infusion (brain heart infusion broth $37 \mathrm{~g} / \mathrm{L}$ ), mucin from porcine stomach type III (Sigma-Aldrich Chemie GmbH, Buchs, Switzerland, $2.5 \mathrm{~g} / \mathrm{L})$, yeast extract $(1 \mathrm{~g} / \mathrm{L})$, L-cysteine $(0.1 \mathrm{~g} / \mathrm{L})$, sodium bicarbonate $(2$ $\mathrm{g} / \mathrm{L})$ and supplemented with hemin $(5 \mathrm{mg} / \mathrm{L})$, menadione $(1 \mathrm{mg} / \mathrm{L})$ and glutamic acid $(0.25 \%)$, and grown anaerobically at $37^{\circ} \mathrm{C}$. For the antimicrobial susceptibility test, the bacterial strains were grown in non-selective blood agar plates (No. 2 of Oxoid; Oxoid Ltd, Basingstoke, UK), with 5\% defibrinated horse blood, hemin $(5 \mathrm{mg} / \mathrm{L})$ and menadione $(1 \mathrm{mg} / \mathrm{L})$, and incubated at $37^{\circ} \mathrm{C}$ under anaerobic conditions for 24-72 hours. Antimicrobial activity testing was carried out by adding a $20 \mu \mathrm{L}$ drop of compound 1 in DMSO on the surface of a bacteria previously inoculated on non-selective blood agar plates; all assays were performed in triplicate. Plates prepared by applying $20 \mu \mathrm{L}$ of a $0.12 \%$ chlorhexidine (CHX) plus $0.05 \%$ cetylpyridinium chloride (CPC) mouthwash, or $20 \mu \mathrm{L}$ of DMSO were used as positive and negative controls, respectively. Antibacterial activity was qualitatively assessed by observing the presence or absence of inhibition zones. The results were classified into three groups (+, $++,+++)$ depending on the area of inhibition: + for poor inhibition,++ for a partial area of inhibition and +++ for a strong area of inhibition, as described by Bonjar ${ }^{20}$. 
Table 1: ${ }^{1} \mathrm{H}$ and ${ }^{13} \mathrm{C}$ NMR data of normulin-11-en-13-oxo-20-oic acid (1) ${ }^{\mathrm{a}, \mathrm{b}}$

\begin{tabular}{|c|c|c|}
\hline $\mathrm{N}^{\circ}$ & $\delta_{\mathrm{H}}(\mathrm{m}, \mathrm{J})$ & $\delta_{\mathrm{C}}(\mathrm{m})$ \\
\hline $1 \alpha$ & $1.99 *$ & $25.1(\mathrm{t})$ \\
\hline $1 \beta$ & $1.56^{*}$ & \\
\hline $2 \alpha$ & $1.94 *$ & $29.0(\mathrm{t})$ \\
\hline $2 \beta$ & $1.21 *$ & \\
\hline 3 & $1.44^{*}$ & $57.6(\mathrm{~d})$ \\
\hline 4 & $1.49^{*}$ & $32.1(\mathrm{~d})$ \\
\hline 5 & - & $58.6(\mathrm{~s})$ \\
\hline $6 \alpha$ & $1.33 \mathrm{~d}(\mathrm{~J}=5.8 \mathrm{~Hz})$ & $32.5(\mathrm{t})$ \\
\hline $6 \beta$ & $2.56 \mathrm{dt}(\mathrm{J}=3.8,8.1 \mathrm{~Hz})$ & \\
\hline $7 \alpha$ & $1.53 *$ & $42.5(\mathrm{t})$ \\
\hline $7 \beta$ & $1.49 *$ & \\
\hline 8 & - & $36.0(\mathrm{~s})$ \\
\hline 9 & $2.47 \mathrm{dd}(\mathrm{J}=11.5,7.0 \mathrm{~Hz})$ & $50.8(\mathrm{~d})$ \\
\hline 10 & $1.83 \mathrm{dd}(\mathrm{J}=11.5,8.4 \mathrm{~Hz})$ & $51.7(\mathrm{~d})$ \\
\hline 11 & $6.27 \mathrm{dd}(\mathrm{J}=13.2,7.0 \mathrm{~Hz})$ & $146.3(d)$ \\
\hline 12 & $5.95 \mathrm{~d}(\mathrm{~J}=13.2 \mathrm{~Hz})$ & $131.0(\mathrm{~d})$ \\
\hline 13 & - & $204.4(\mathrm{~s})$ \\
\hline $14 \alpha$ & $2.69 \mathrm{ddd}(\mathrm{J}=13.2,8.7,4.5 \mathrm{~Hz})$ & $39.9(\mathrm{t})$ \\
\hline $14 \beta$ & $2.49 \mathrm{~m}$ & \\
\hline $15 \alpha$ & $2.30 \mathrm{~m}$ & $29.2(\mathrm{t})$ \\
\hline $15 \beta$ & $1.20 \mathrm{~m}$ & \\
\hline 17 & $1.08 \mathrm{~s}$ & $27.3(q)$ \\
\hline 18 & $0.87 \mathrm{~d}(\mathrm{~J}=5.9 \mathrm{~Hz})$ & $23.0(\mathrm{q})$ \\
\hline 19 & $1.05 \mathrm{~d}(\mathrm{~J}=5.8 \mathrm{~Hz})$ & $22.8(\mathrm{q})$ \\
\hline 20 & $9.53 \mathrm{~s}$ & $180.0(\mathrm{~s})$ \\
\hline
\end{tabular}

* Overlapped signal.

${ }^{\mathrm{a}}$ Chemical shifts are $\delta$ values (ppm) from TMS.

${ }^{b} 2 \mathrm{D}{ }^{1} \mathrm{H},{ }^{1} \mathrm{H}(\mathrm{COSY})$ and ${ }^{13} \mathrm{C},{ }^{1} \mathrm{H}$ (HSQC) NMR experiments confirmed the correlations of all protons and corresponding carbons.

${ }^{\mathrm{c}}$ Multiplicities were assigned with DEPT.

\section{RESULTS AND DISCUSSION}

The aerial part of $A$. compacta collected at Tatio (northern Chile) was grounded and extracted with hexane. Compound 1 (Figure 1) and six known diterpenes (Figure 2) were isolated from this extract. Known compounds were identified by comparison with authentic samples and with data from the literature ${ }^{13-17}$. Compound $\mathbf{1}$ was isolated as a colorless solid. The ultraviolet spectrum shows a maximum absorption at $232.5 \mathrm{~nm}$, whereas in the infrared spectrum absorptions corresponding to hydroxyl group $\left(3424 \mathrm{~cm}^{-1}\right)$ and carbonyl functions $\left(1692\right.$ and $\left.1639 \mathrm{~cm}^{-1}\right)$ are observed.

The structure shown in Figure 1 was mainly determined by Mass and NMR spectroscopies. EIMS fragmentation of $\mathbf{1}$ suggests a molecular formula of $\mathrm{C}_{19} \mathrm{H}_{28} \mathrm{O}_{3}$ (molar mass: $304.43 \mathrm{Da}$ ), whereas the peak at $\mathrm{m} / \mathrm{z} 258.0$ corresponding to loss of $44.06 \mathrm{Da}$ is indicative of a $\mathrm{CO}_{2}$ system from rupture of carboxylic acid. Analogously, the loss of two fragments with values of 13.0 and $28.0 \mathrm{Da}$ suggests the presence of an isopropyl group, which is a structural feature of diterpenes isolated from the Azorella genus. ${ }^{13} \mathrm{C}$ NMR spectrum of compound 1 confirms the presence of 19 carbons: 3 methyl, 6 methylenes, 6 methines and 4 quaternary carbons (two carbonyl groups). Signals appearing at $\delta 204.4$ and $179.9 \mathrm{ppm}$ show the existence of two carbonyl groups, while signals at $\delta$ 130.6 and $145.9 \mathrm{ppm}$ are assigned to olefinic carbons. These data suggest a $\alpha$, $\beta$ unsaturated ketone structure. Additionally, a signal at $\delta 179.98 \mathrm{ppm}$ indicates the presence of a carboxylic group. In the ${ }^{1} \mathrm{H}$ RMN spectrum, signals at $\delta 6.27$ $(1 \mathrm{H}, \mathrm{dd}, \mathrm{J}=13.2,6.9 \mathrm{~Hz}, \mathrm{H}-11)$ and $5.95(1 \mathrm{H}, \mathrm{d}, \mathrm{J}=13.2 \mathrm{~Hz}, \mathrm{H}-12) \mathrm{ppm}$ confirm the presence of a $\mathrm{Z}$ double bond, whereas the signal multiplicity at $\delta$ $6.27 \mathrm{ppm}$ allows to establish the olefinic position. The existence of an isopropyl group is confirmed by signals appearing at $\delta_{\mathrm{C}} 23.0$ and $22.8 \mathrm{ppm}$ and $\delta_{\mathrm{H}} 0.87$ $(3 \mathrm{H}, \mathrm{d}, \mathrm{J}=5.9 \mathrm{~Hz})$ and $1.05(3 \mathrm{H}, \mathrm{d}, \mathrm{J}=5.8 \mathrm{~Hz}) \mathrm{ppm}$, respectively. Also, signals at $\delta_{\mathrm{C}} 26.9$ and $\delta_{\mathrm{H}} 1.08 \mathrm{ppm}$ are associated to a methyl group (s, Me-17), that is part of the skeleton. All these features strongly suggest that compound 1 has a mulinane skeleton without methyl 16 , the methyl group which is usually present in the seven carbon ring (see Figure 1).

The stereochemistry of C-9 was determined by calculating the dihedral angle between $\mathrm{H}-9$ and $\mathrm{H}-10$ to get a theoretical coupling constant. This value was compared with experimental $\mathrm{J}$ obtained from the ${ }^{1} \mathrm{H}$ spectrum in benzene as solvent; $\delta$ (ppm) 2.37 (dd, $J=7.0$ and $10.9 \mathrm{~Hz}, 1 \mathrm{H}, \mathrm{H}-9)$ and 5.89 (dd, $J=7.0$ and $13.1 \mathrm{~Hz}, 1 \mathrm{H}, \mathrm{H}-10$ ). As can be seen in Figure 1, both protons are trans. The proposed stereochemistry is congruent with that reported for other mulinane diterpenes. Thus, the data confirm that compound $\mathbf{1}$ is a norditerpene that has not been isolated from any natural sources previously.

Actually, the search for natural compounds exhibiting antimicrobial activity, especially against oral bacteria, is a matter of current interest ${ }^{21}$ Extracts and metabolites obtained both from terrestrial ${ }^{22}$ and marine ${ }^{23}$ sources have been assayed against a variety of oral bacteria.

The antibacterial activity of compound $\mathbf{1}$ was assessed against a group of oral. The results indicate that $\mathbf{1}$ exhibits different levels of inhibition effect on growth of these bacteria. Thus, $\mathbf{1}$ has not effect on $V$. parvula growth, and reduces slightly the growth of $A$. actinomycetemcomitans. However, the level of growth inhibition against $A$. naeslundii, $S$. oralis and $P$. gingivalis is similar to that observed for the positive control. Similar results were obtained for compound $\mathbf{1}$ incorporated to polymer micelles formed by Pluronic F-127. Growth inhibition of Gram-positive (A. naeslundii, S. oralis) and Gramnegative bacteria ( $F$. nucleatum and $P$. gingivalis) is an interesting feature that opens the field for more extensive studies, because the last two are important periodontal pathogens. The table 1 summarizes the antibacterial effect of compound 1 and compound 1 in micelles.

Table 1: Antibacterial activity of compound 1

\begin{tabular}{|c|c|c|c|}
\hline Oral bacteria & $\begin{array}{c}\text { Positive } \\
\text { control }\end{array}$ & Compound 1 & $\begin{array}{c}\text { Compound } \\
1 \text { micelles }\end{array}$ \\
\hline A. actinomycetemcomitans & +++ & + & + \\
\hline A. naeslundii & +++ & +++ & +++ \\
\hline F. nucleatum & +++ & ++ & ++ \\
\hline P. gingivalis & +++ & +++ & +++ \\
\hline S. oralis & +++ & +++ & +++ \\
\hline
\end{tabular}

The results were classified into three groups $(+,++,+++)$ depending on the area of inhibition: + for poor inhibition, ++ for a partial area of inhibition and +++ for a strong area of inhibition. Positive control is an aqueous mixture of chlorhexidine $(0.12 \%)$ plus cetylpyridinium chloride $(0.05 \%)$.

\section{CONCLUSIONS}

Attention has rarely been paid to minor compounds of Azorella compacta that may exhibit biological activity. In this study, normulin-11-en-13-oxo-20oic acid was isolated from the hexane extract in very low quantity. Compound $\mathbf{1}$ is a norditerpene with a mulinane skeleton lacking the 16-methyl group, and this is the first report of its existence in a natural source. The chemical structure of this compound was determined by using different spectroscopic methods and data that have been already reported for other diterpenes found in this plant.

Interestingly, compound $\mathbf{1}$ shows an important growth inhibition effect against different strains of buccal bacteria. More specifically, the results obtained with Aggregatibacter actinomycetemcomitans and Actinomyces naesludii, stand out over the rest because $\mathbf{1}$ shows similar activity to that obtained for the positive control, i.e. a mixture of $0.12 \%$ chlorhexidine and $0.05 \%$ CPC.

Finally, the results presented in this study open a potential new biological application for this plant, based specifically on the diterpene content that it produces. Thus, new alternatives may be explored on future research regarding bioactivity of Azorella compacta. 


\section{ACKNOWLEDGMENTS}

This research was supported by Fondecyt project $\mathrm{N}^{\circ} 1120199$. M. Bacho is grateful to CONICYT for a national doctorate scholarship $\mathrm{N}^{\circ} 21110474$

\section{REFERENCES}

1. J. R. Hanson Nat. Prod. Rep., 21, 312 (2004)

2. L. Quesada, C. Areche, L. Astudillo, M. Gutierrez, B. Sepulveda, and A. San-Martín, Nat. Prod. Commun., 7, 1187 (2012)

3. J. Borquez, A. Ardiles, L. A. Loyola, L. M. Pena-Rodriguez, G. M. MolinaSalinas, J. Vallejos, I. G. Collado, and M. J. Simirgiotis Molecules, 19, 3898 (2014)

4. A. San-Martín, V. Donoso, S. Leiva, M. Bacho, S. Nunez, M. Gutierrez, J. Rovirosa, N. Bailon-Moscoso, S. C. Camacho, O. M. Aviles, and M. E. Cazar Curr. Top. Med. Chem., 15, 1743 (2015)

5. L. A. Loyola, J. Borquez, G. Morales, J. Araya, I. Neira, H. Sagua, and A. San-Martín. Bol. Soc. Chil. Quim., 46, 9 (2001)

6. C. Areche, P. Cejas, P. Thomas, A. San-Martín, L. Astudillo, M. Gutiérrez, and L. A. Loyola Quim. Nova, 32, 2023 (2009)

7. L. Astudillo, M. Gutierrez, L. Quesada, A. San-Martín, L. Espinoza, and P. Penailillo Nat. Prod. Commun., 9, 9 (2014)

8. M. A. Munoz, A. San-Martín, and P. Joseph-Nathan Nat. Prod. Commun., $10,1343(2015)$

9. K. P. Reber, J. Xu, and C. A. Guerrero J. Org. Chem., 80, 2397 (2015)

10. C. B. Colloca, D. B. Pappano, D. A. Bustos, V. E. Sosa, R. F. Baggio, M. T. Garland, and R. R. Gil Phytochem., 65, 2085 (2004)

11. S. Lopez, B. Lima, M. B. Aguero, M. L. Lopez, M. Hadad, J. Zygadlo, D.
Caballero, R. Stariolo, E. Suero, G. Feresin and A. Tapia, Arabic Journal of Chemistry, 11, 2, 187 (2014)

12. F. Salgado, C. Areche, B. Sepulveda, M. J. Simirgiotis, F. Caceres, C. Quispe, L. Quispe, and T. Cano Pharmacogn. Mag., 10, 543 (2014)

13. L. A. Loyola, G. Morales, B. Rodriguez, J. Jimenezbarbero, S. Pedreros, M. C. Delatorre, and A. Perales J. Nat. Prod., 54, 1404 (1991)

14. L. A. Loyola, J. Borquez, G. Morales, A. San-Martín, V. Manriquez, and O. Wittke Tetrahedron, 54, 15533 (1998)

15. G. A. Wachter, G. Matooq, J. J. Hoffmann, W. M. Maiese, M. P. Singh, G. Montenegro, and B. N. Timmermann J. Nat. Prod., 62, 1319 (1999)

16. J. Borquez, L. A. Loyola, G. Morales, A. San-Martín, R. Roldan, N. Marquez, and E. Munoz Phytother. Res., 21, 1082 (2007)

17. G. M. Molina-Salinas, J. Borquez, A. Ardiles, S. Said-Fernandez, L. A. Loyola, A. Yam-Puc, P. Becerril-Montes, F. Escalante-Erosa, A. SanMartín, I. Gonzalez-Collado, and L. M. Pena-Rodríguez Phytochem. Rev., 9, $271(2010)$

18. A. F. Olea, H. Carrasco, L. Espinoza, and B. Acevedo J. Chil. Chem. Soc., 59, $2451(2014)$

19. L. Taborga, K. Diaz, A. F. Olea, P. Reyes-Bravo, M. E. Flores, H. PenaCortes, and L. Espinoza J. Agric. Food Chem., 63, 6890 (2015)

20. S. Bonjar J. Ethnopharmacol., 94, 301 (2004)

21. A. Souza, C. Martins, M. Souza, N. Furtado, V. Heleno, J. de Sousa, E. Rocha, J. Bastos, W. Cunha, R. Veneziani, S. Ambrósio, Phytotherapy Research, 25, 2, 215 (2011)

22. T. Suman, V. Anuradha, R. Devi, Journal of Pure and Applied Microbiology, 4, 1, 231 (2010)

23. J. Rovirosa, V. Blanc, R. Leon, A. San-Martín, J. Chil. Chem. Soc., 58, 4, 2025 (2013) 